\title{
Crime Mapping Model based on Cloud and Spatial Data: A Case Study of Zambia Police Service
}

\author{
Jonathan Phiri ${ }^{1}$, Charles S. Lubobya ${ }^{3}$ \\ Department of Electrical and Electronic Engineering \\ University of Zambia \\ Lusaka, Zambia
}

\author{
Jackson Phiri ${ }^{2}$ \\ Department of Computer Science \\ University of Zambia \\ Lusaka, Zambia
}

\begin{abstract}
Crime mapping is a strategy used to detect and prevent crime in the police service. The technique involves the use of geographical maps to help crime analysts identify and profile crimes committed in different residential areas, as well as determining best methods of responding. The development of geographic information system (GIS) technologies and spatial analysis applications coupled with cloud computing have significantly improved the ability of crime analysts to perform this crime mapping function. The aim of this research is to automate the processes involved in crime mapping using spatial data. A baseline study was conducted to identify the challenges in the current crime mapping system used by the Zambia Police Service. The results show that $85.2 \%$ of the stations conduct crime mapping using physical geographical maps and pins placed on the map while $14.8 \%$ indicated that they don't use any form of crime mapping technique. In addition, the study revealed that all stations that participated in the study collect and process the crime reports and statistics manually and keep the results in books and papers. The results of the baseline study were used to develop the business processes and a crime mapping model, this was implemented successfully. The proposed model includes a spatial data visualization of crime data based on Google map. The proposed model is based on the Cloud Architecture, Android Mobile Application, Web Application, Google Map API and Java programming language. A prototype was successfully developed and the test results of the proposed system show improved data visualization and reporting of crime data with reduced dependency on manual transactions. It also proved to be more effective than the current system.
\end{abstract}

Keywords-Zambia police; web application; mobile application; cloud model; crime mapping; spatial data

\section{INTRODUCTION}

Challenges in preventing and reducing crimes are what most governments around the world are struggling to deal with, every family and business have been directly affected by different kinds of crimes like robberies, vandalism, burglaries, sexual and other crimes [1].Crimes affect the quality of life, economic growth, and reputation of a nation. There is need for the law enforcements to take tough preventive measures to reduce crimes in communities [2]. In Zambia the Zambia Police is considered as the main law enforcement agency mandated to enforce law on Zambian citizens and combat crime thereby playing a critical role in the Zambian criminal justice system [3]. A criminal justice system comprises of government institutions mandated to detect and mitigate crime, it focuses on how criminal cases flow from the time they are reported and investigated up to when they are disposed off. A well established and effective criminal justice system is the key to the reduction of crime in a nation [4] . Ordinary citizens and communities in a Government expect the criminal justice system and its general capacity to not only protect the communities and deal with criminal offenders but also interact with different various parties including victims, witnesses, accused as well as criminal justice professionals [5], therefore the Zambia police being the first to have contact with these people can be regarded as the gate keeper of the Zambian justice system. The Zambia Police was established in 1891 under British South African Company known as Northern Rhodesia police force, and later in 1964 upon attainment of independence was established then under Article 103 (3) of the constitution and now under Article 193 (2) of the 2016 amended constitution of Zambia and also under the Zambia Police amendment act number 30 of 2016 of the laws of Zambia, the name was changed from Northern Rhodesia to Zambia Police force which later in 1994 changed to Zambia police service. Article 193 (2) of the 2016 amended constitution clearly outlines the roles and functions of the Zambia police service, it mandates the agency to ensure protection of life and property, preservation of peace, maintenance of law and order, upholding bill of rights and most importantly detect and prevent crime [6]. One of the key strategies used to detect and prevent crime is crime mapping. The technique involves the use of geographical maps to help crime analysts identify and profile crimes committed in different residential areas, as well as crafting best methods of responding [7]. It facilitates visual and statistical analysis of spatial crime data for a specific area by linking it with geographical variables like bars, schools, streets and others. Crime does not spread across the space evenly or equally but rather clumps on some specific areas while absent in other areas. Crime mapping is devoted at identifying high crime areas or neighborhoods also known as hotspots, hotspots are areas with high criminal activities [8]. Proactive policing pushes police officers to identify areas with high concentration of crimes, determine what causes these concentrations and find methods of reducing these concentrations [9]. A well and clearly visualized crime hotspot map significantly helps police officers in aiding threat visualization, police resource allocation and crime prediction. The development of geographic information system (GIS) technologies and spatial analysis applications coupled with cloud computing have significantly improved the ability of crime analysts to perform this crime mapping function [10]. However, the Zambia Police Service is 
still using the manual and traditional way of mapping crimes, crime data management and crime data visualization. All crime data and records are stored in books and papers. Crimes are mapped using physical geographical maps and pins to establish the location of crime areas. It is so complex to keep track of criminal activities and statistics in crime hotspot areas using paper based system. The manual and paper based crime mapping system that is in place does not provide the needed efficiency and effectiveness to the management of crime maps and crime data.

The focus of the study is on computerizing the crime mapping processes by using cloud architecture and spatial data.

This paper is organized as follows: The second section is literature review which covers technologies used in crime mapping and cloud computing, it also covers the related works which looks at the systems that have previously been designed and implemented to solve challenges of the similar nature. Third section presents the methodology, fourth section brings out the results, the fifth section presents the discussion of the baseline study and development of the prototype crime mapping system, the sixth section presents the conclusion and the last section presents recommendations and future works.

\section{LITERATURE REVIEW}

A crime is defined as the breach of criminal law that govern a particular geographical area, the criminal law that aims at protecting the lives, property and rights of citizens within a particular jurisdiction [11].In addition ,Harries [12] describes a crime in four dimensions; Legal - a law must be broken, Victim - someone or something has to be targeted, Offender - someone has to do the crime and Spatial - a crime has to happen at a place somewhere in space and time, commonly referred to as crime spatial data. Spatial data is data that describes the location, shape and relationship of geographic features [13].In criminology it is called spatial crime data because it contains geographical referenced attributes like geographical coordinates (longitude and Latitude) that can be used to establish the exact location of an object or crime incident on the map [14].Crime mapping seeks to answer the question of "where"?" for example, "where does crime happen?" or "Where should we focus efforts to catch a serial killer?" or "Where should we build a new police station to fight the crime?" or "Where is crime highest?" by analyzing the crime spatial data provided from various sources [15].Daglar and Argum [16]in their paper highlighted that a place of a crime and any other geographic information connected with a criminal incident can give a lot of information about characteristics of possible criminals, it can also assist in designing of assessment and prevention programs for the related crime incidents. They added that deciding a policing method is always influenced by some facts of place such as jurisdictions, zones, and incident locations are all related to geography. This section will present the history of crime mapping, crime mapping technologies, cloud computing and related works.

\section{A. History of Crime Mapping}

The use of traditional crime pin maps for data visualization dates back in early 1830 s. The crime map was a representation of pins stuck on it, the pins on the map were useful for showing where crimes occurred [12].There are three schools that were recognized and pointed out in the study by Philips [14],the first was called cartographic/geographic school which dominated between 1830s and 1880s originated from France and later spread to England. In this work, government begun to collect social data, the intended purpose was to center on the influence of variables such as wealth and population density on levels of crime. The second was called Typological school which dominated between $1880 \mathrm{~s}$ and 1900s, it focused on the relationship between the mental and physical characteristics of people and crime. The third was called Social ecological school which has dominated from 1900s up to date, it concentrated on the geographical variations on social conditions assuming that they were related to crime patterns. It focused primarily on recognizing and classifying areas in the cities with similar social characteristics [12].

\section{B. Crime Mapping Technologies}

The manual and traditional pin maps had a number of limitations among them were loss of data as they were updated and also the maps were static, they could not be manipulated or queried. Mapping of crimes has become a primary function in law enforcement agencies, the advancements in computing have facilitated the development of geographical system and spatial technologies. There are three main categories of spatial technologies that can be used for crime mapping [17];

1) Open source maps: These are maps that available over the internet for free, examples of common open source maps are google maps, Bing maps and open-street maps. Crime analysts are able to perform basic crime mapping duties at free cost. The disadvantage of open source maps is that crime analysts cannot perform complex queries.

2) GIS-Software: These tools are commercial, they provide the necessary geospatial analytical functions needed for basic, intermediate and advanced mapping queries. The main disadvantage of GIS-software is the high cost of acquiring a license, it also requires special training.

3) Online dashboard: In this category, law enforcement agencies outsource the crime mapping duties from agencies outside the law enforcement. Agencies like Bair Analytics can provide crime mapping services at a nominal fee. The main advantage of outsourcing is that it reduces the workload of geocoding and data organization. It also provides better data storage and security as data is stored via cloud-storage.

The advancement in computing has also led to the use of artificial intelligence technologies like machine and deep learning models to predict future crime occurrences [18], this approach is known as predicting policing. Predictive policing involves the use of analytical techniques to identify either likely places of future crime scenes or past crime perpetrators, by applying statistical predictions [19].

Machine Learning can be described as a field of computer science that evolved from studying pattern recognition and computational learning theory in artificial intelligence. It is the learning and building of algorithms that can learn from and make predictions on data sets [20]. It is regarded as the field of 
study that gives computers the ability to learn without being explicitly programmed. The main purpose of machine learning is to learn from the data without any human intervention [21]. There are three main categories of machine learning algorithms namely supervised, unsupervised and semi-supervised machine leaning algorithms. The algorithms in the Supervised Machine learning are those that need external assistance, in this category, the provided input dataset is divided into train and test dataset. The train dataset has output variable which needs to be predicted or classified. All algorithms learn some kind of patterns from the training dataset and apply them to the test dataset for prediction or classification [22]. There are three types of supervised machine learning algorithm, the first is Decision trees - Decision tree is used mainly for classification purpose where attributes of groups are sorted based on their values. Each decision tree consists of nodes and branches, a node represents attributes in a group that is to be classified and a branch represents a value that the node can take. The second is Naïve Bayes -This algorithm manly focuses on classification of text, it mainly depends on conditional probability of events. The third is Support Vector Machine (SVM)-It mainly focuses on calculation and classification of margins, it basically draws the margins between the classes. The algorithms in the Unsupervised Machine Learning learn few features from the input pattern or data, the learning data is divided into different clusters hence referred to as a clustering algorithm. When new data is introduced, it uses the previously learned features to recognize the class of the data. It is mainly used for clustering and feature reduction [23]. There are two types of unsupervised machine learning algorithms, the first one is K-Means Clustering- is a type of unsupervised learning technique that automatically create groups when initiated. The items which possess similar characteristics are put in the same cluster creating K-district clusters hence called K-means clustering algorithm. The second is Principal Component Analysis or PCA, in this algorithm, the dimension of the data is reduced to make the computations faster and easier. The algorithm in the semi-supervised machine is the combination of both the power of supervised and unsupervised learning. It is mostly ideal and fruitful in areas such as data mining where there is a presence of unlabeled data and getting the labeled data is deemed a tedious process. Some of the semi-supervised models include generative model, self-training model and transductive model.

Deep Learning is also utilized to predict crimes using different techniques [24]. It is regarded as the newly introduced area of machine learning and artificial intelligence comprising of multiple hidden layers of artificial neural networks. Its roots are derived from an Artificial Neuron Network (ANN) introduced by Kunihiko Fukushima in 1980. An ANN can be described as an interconnected network of processing units emulating the network of neurons in the brain [25]. Deep learning has two main categories namely deep neural networks and convolutional neural networks. A Deep Neural Network (DNN) is an artificial neural network (ANN) that has multiple hidden layers of units between the input and output layers capable of modeling complex non-linear relationships [26]. Convolutional neural networks (CNNs) are an artificial neural network that use convolution in place of general matrix multiplication in at least one of their layers. They use used tied weights and pooling layers, this allows them to take advantage of the 2D structure of input data. They can be used in both image and speech applications [27].

\section{Cloud Computing}

The other technology that has emerged, developed so fast and contributed to the spatial data technology is cloud computing. The evolution of GIS technology and of spatial information acquisition technology have led to more and more collection of spatial data through various approaches for different services like emergence services, crime mapping and other reasons, this has caused the demand for high information processes and computing environment [28]. Cloud computing has emerged as a technology primarily focusing on large scale resource sharing and low cost for big data storage technology. Cloud computing has proved to be an emerging technology capable of providing business models for organizations to utilize deferent computing services at a minimum cost. Cloud is defined as a metaphor describing a web as a space where computing has been preinstalled and exist as a pool of services such as information, infrastructure, applications, storage and processing power on the web ready to be shared [29]. The cloud computing architecture consists of the front end and back end components [30] as shown in Fig. 1. An internet connectivity is required to effect communications between the client and the backend.

The front end is referred to as a client part of cloud computing system which consists of interfaces, networks and applications that are required to access the cloud computing platforms. The back End also referred to as a cloud itself, consists of all the resources required to provide cloud computing services. It comprises of huge data storage, virtual machines, security mechanism, services, deployment models, servers and many others that can be accessed securely accessed over the internet or private connection [32]. Cloud computing offers three key service models namely Software as a Service (SaaS), Platform as Service (PaaS) and Infrastructure as a Service (IaaS) [33] as shown in Fig. 2.

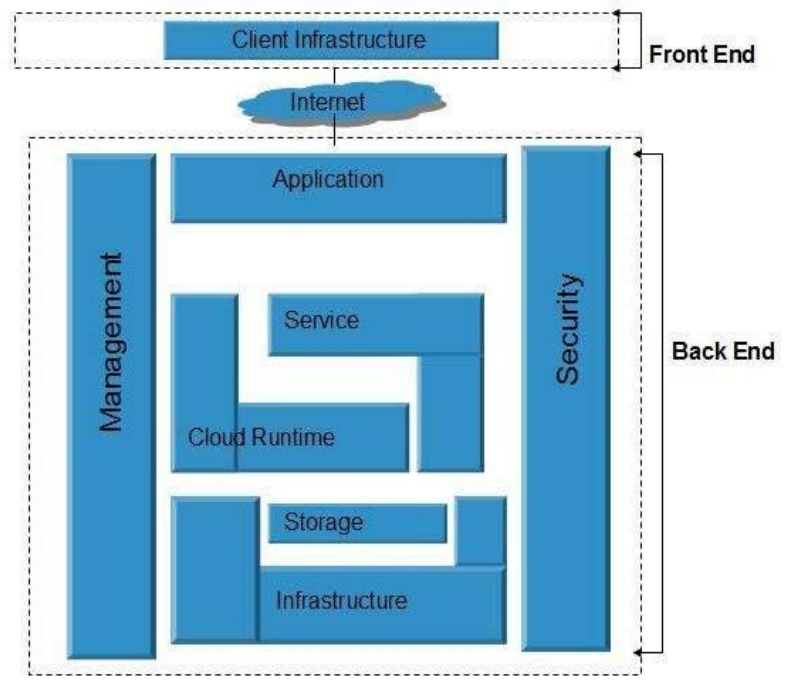

Fig. 1. Cloud Computing Architecture [31]. 


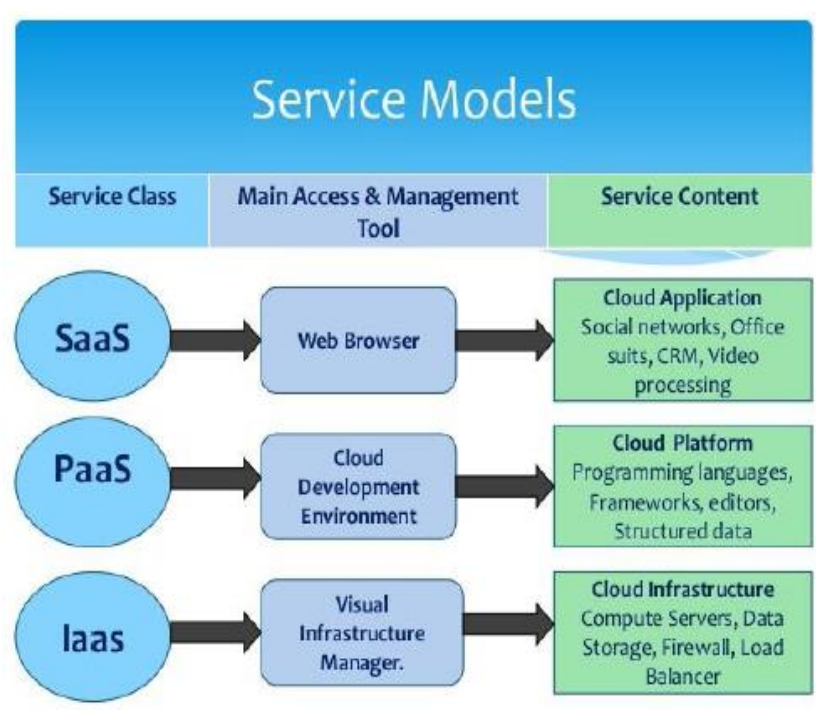

Fig. 2. Cloud Service Model [34].

Software as a service (Saas) delivery model in which software applications are hosted by a vendor or service provider and made available to customers over a network, typically the Internet, the clients can purchase and install the application onto personal computers. Platform as a service (Paas) is a delivery model in which clients are provided with the environment for development and deployment of web based applications using required tools like already created library, pattern, services, programming language and many others. Clients cannot manage the servers, operating system, storage and network but they have control over the deployed web applications including re-configuring the applications. Infrastructure as a service (IAAS) delivery model is where users are allocated with computing resources like operating system, servicers, networks, storage media and others in order to run their applications [34]. There are five models in which cloud computing can be deployed namely public cloud, private cloud, community cloud and hybrid cloud models [35]. The public cloud is where all the computer systems and services are accessible and available to the general public or a large industry group. The private cloud is where computer systems and services are available and restricted to only an organization and that organization is given greater control, security and privacy. The hybrid cloud is where both public and private cloud are combined to offer a common service, on-critical activities are performed using public cloud and critical activities are performed using private cloud. It is mostly used for archiving and backing up of data by replicating local data to a public cloud. The community cloud is used and controlled by a group of organization from specific communities that have similar and common computing requirements and interests [35].

With the continuous historic advancement in technology and high demand for data sharing, cloud computing has been recognized as the most flexible delivery model for ICT resources [36]. According to [37]in their paper they proposed an approach which employs cloud-based service to solve the big spatial data technology in emergence management for better spatial analysis. Mwansa and Phiri in their paper [38] developed a model for the inventory system based on quick response and cloud computing integrated with mobile application for real-time capture of grain bags brought in by farmers at the setline depot. The results of the system showed an improved and acceleration of grain stock statistics in realtime.

\section{Related Works}

Most Police stations and other law enforcement agencies in developed countries like USA and UK already migrated from traditional pin maps to computerized crime mapping systems [39]. The police in most developing countries like Africa are not equipped with infrastructure like GPS and GIS technologies for mapping of crime. The infrastructure is not only expensive to acquire but also time consuming when setting it up, it requires trained people to operate and manage it. But the benefits of viewing data in the form of a map are massive as compared to grasping tabular or manual data of crime incidents [40]. In Africa, South Africa is considered as more progressive than any other country in Africa in terms of usage of ICTs. In 2000 the South African Police Service (SAPS) through the crime information center developed the National crime GIS database that could allow SAPS to link crime statistics with police boundaries as well as exploring the relationship between crime types and social demographic variables through the use of multivariate statistical techniques. In addition, the author highlights that currently the predominant information system used by SAPS is Case Administration System (CAS) which is regarded as the primary source of information on victims and offenders. It is integrated with a case docket management system that gathers information at a police station level on crime cases such as address and time of crime. The challenge is that CAS is not yet fully accessible country wide and it has not been linked with any GIS technology making crime spatial description and interpretation of criminal activities impossible [41].

Tong in her paper [42] also proposed a crowdsourcing based crime mapping system, it's a system based on cloud architecture integrated with iPhone mobile application. The system composed of a server running in the cloud and a client application that includes a website and iPhone mobile application to enable users to interact with crime contents. The system gathered both crime reports from the crowd together with crime contents and displayed them on a crime map. Users of the system are able to review and comment on crime incident on a digital crime map.

Singh et al. [43] in their paper proposed and developed a cloud GIS crime mapping blog that could be used by the police for crime mapping. The system generates daily, weekly and monthly crime maps which would help to identify crime patterns and clusters. The crimes in the blog are categorized into theft, murder, snatching and other classes, the system was developed on a cloud architecture using Google cloud and Google maps as source of spatial data. The system uses RSS (Really Simple Syndication) feeds from various news websites as a source of crime data, meaning that crime related news is manually extracted from the collection of news and formatted into desired format with attributes like location, type of crime, details and link to the news web page. The location data is further transformed into georeferenced data, the process 
commonly known as geocoding. Geocoding is described as the process of converting or transforming a description of a location such as pair of coordinates, an address into a location on the earth's surface and used to point a location in the GIS digital map [44]. Depending on the details of the address, this could be a specific building, the center point of a road, or the center point of an area [45]. Geocoding technique requires special skills and training. The limitation of this system is that the location of the crime specified in the news is generalized therefore the generated point location is not very accurate.

Mwiya et al. [46] proposed and developed a public crime reporting system for the Zambia Police, a cloud \& GSM based android mobile application (prototype) to help the general public to only report crime cases using mobile devices. The limitation of this system is that it does not map crime areas.

Some of the solutions provided by applications in the related works would be of great benefit if adopted in the crime mapping model for the Zambia Police. Due to unavailability of digital historical crime dataset from the Zambia Police, the source of crime data for the proposed system is the live crime reports from the general public, to achieve this, a crime reporting component would be added to the system consisting of a web application and mobile application. In order to enhance accuracy, users would specify crime location by selecting a name of the location from the Google map, then the system saves the georeferenced data into the cloud database. The benefit of this approach is that it does not require crime data to be geocoded to produce crime maps as everything would be done by the system.

\section{METHODOLOGY}

This section of the study presents the materials and methods used to conduct the baseline study, this includes methodology used to design the model then followed by mapping of business process.

\section{A. Baseline Study}

The purpose of the baseline study was to identify challenges in the current crime mapping system used by the Zambia Police. To archive this, different materials \& methods were used;

1) Data collection: Primary data was collected from police officers based in Lusaka working in the CID and VSU departments through the use of interviews \& structured questionnaires. Further, general members of public were also interviewed through self-administered questionnaires. Openended and closed-ended questions were included in the questionnaires to capture both the qualitative and quantitative responses.

2) Population and sample: The population considered for this study was the Lusaka based police officers. Purposive sampling method was used to select 88 police officers from ten different police stations across Lusaka District. Further, a combination of random and convenient sampling method was used to select members of public who were visiting the police stations for various reasons.
3) Data analysis and presentation: Data was entered, analyzed and presented using the Statistical Package for Social Scientists (SPSS) version 16. The analysis was mainly descriptive in nature.

\section{B. Model Design Methodology}

The proposed model was designed using Cloud Architecture, Android Mobile Application, Web Application, Google Map API and java Programming Language. The web application consists of a client and server architecture where a client is a browser and server is the cloud firebase thus include firebase-database for data storage.

\section{Mapping Business Processes}

Fig. 3 shows the crime mapping business processes for the current crime mapping system,

As shown in Fig. 3, crime mapping process begins at the time when a crime is officially reported by a member of public. The case including all the details of the complainant and suspect if any are recorded into an occurrence book by an officer on duty at the front desk known as inquiries. Thereafter the case is forwarded to the CIO for review, approval and assigning of case to an investigator. The investigating officer investigates \& analyze a crime by placing a pin on a geographical map depicting its location. The investigating officer forward the case details to the Records/Statistics officer who enters the case into the crime register for record purposes. The records/Statistics officer generates crime statistics and share the information with an investigation officer and others.

The Proposed automated crime mapping business processes are derived from the current business processes presented in Fig. 3. The proposed model is designed in two parts, the mobile application to be used by the general public to report crimes and also the Web application to be used by the police to not only capture and view crime reports but also generate crime statistics and crime maps. Fig. 4 shows the proposed web application.

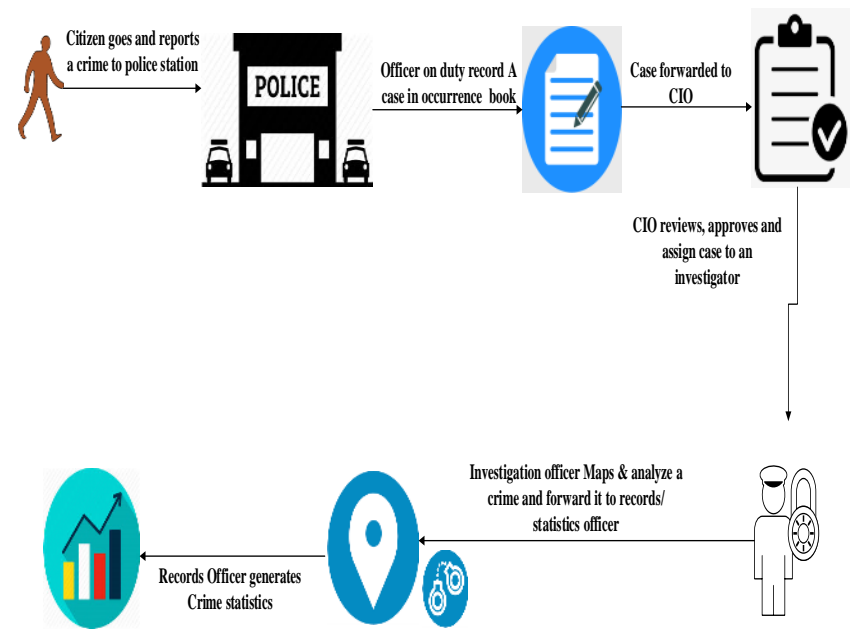

Fig. 3. Current Crime Mapping Business Processes. 
As shown in Fig. 4, a crime is directly reported by a member of the public, the officer on duty records the crime case into the system, the GPS satellite through Google maps captures not only the actual location of crime but also residential address of both the complainant and suspect, the case details including geo-referenced data will be saved into the cloud database. The case is automatically forwarded to the CIO for assigning, upon assigning the case to the investigator, the case is added to the crime register and automatically updates the crime map. Both the crime investigator \& statistics/records officers will be able to view and generate crime maps \& reports. Fig. 5 shows the proposed mobile application business processes.

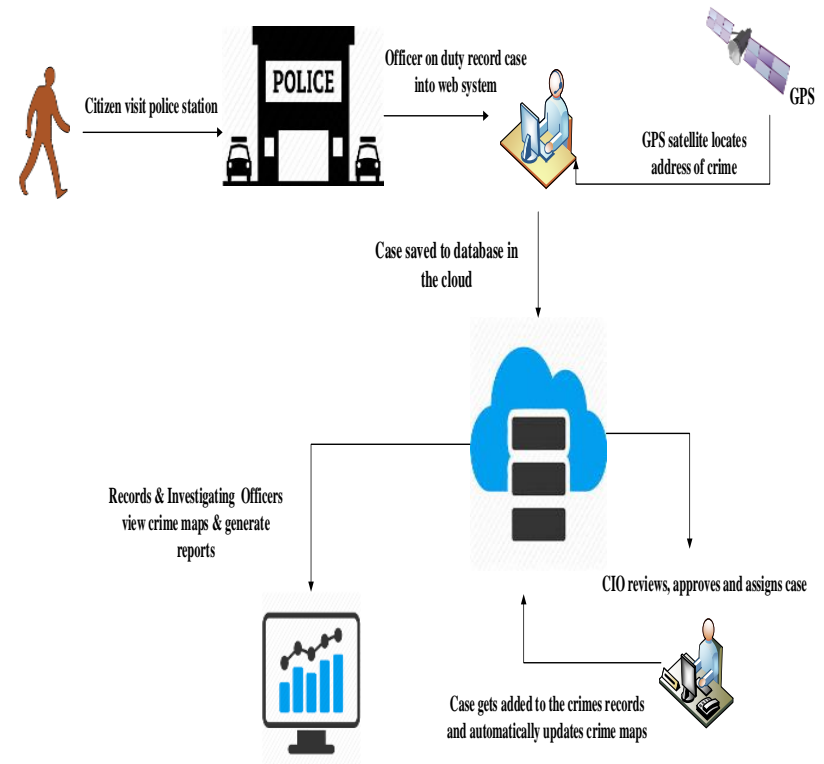

Fig. 4. Proposed Business Processes - Web Application.

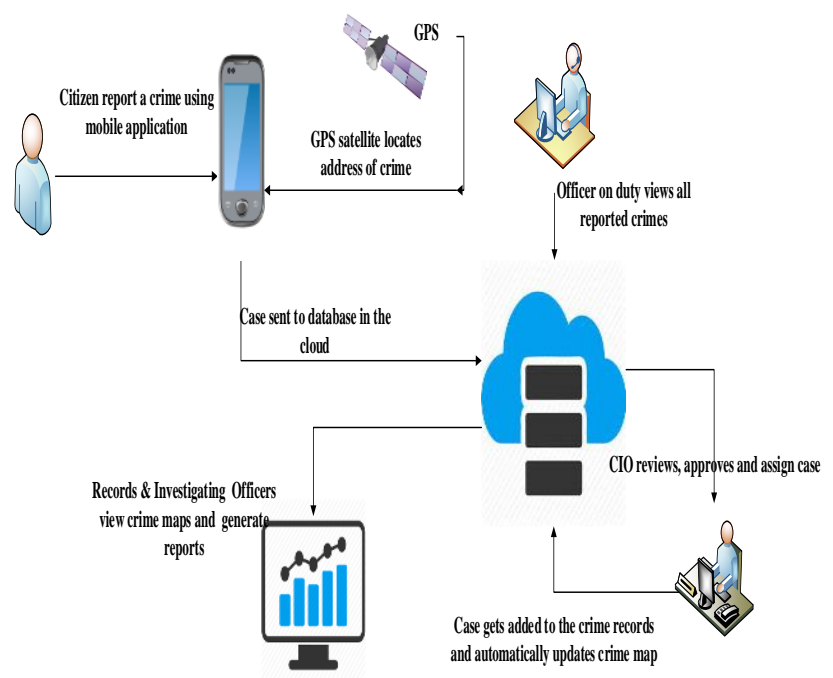

Fig. 5. Proposed Business Processes - Mobile Application.
The mobile application allows the citizen/user to report crime case using a mobile device. The police will use the web platform to view the reported crimes and map them. The citizens are also able to view the status of the case they reported.

\section{Proposed System Architecture}

The proposed system architecture shown in Fig. 6 utilizes the private cloud infrastructure where ZAMTEL the largest telecommunications company in Zambia provides the MPLS network while Zambia Police provides the private cloud services. The MPLS backbone comprises of fiber and microwave.

As shown in Fig. 6, Zambia Police exclusively operates computing resources in the cloud in which different servers are installed such as Email server, Database server, Application server, Web server, Real-time communication server and many others. The rationale herein is to make sure the system is accessed by different police stations located across the country thus include the general public who are the mobile application users with less convenience of configuring hardware, software and security of information. The proposed architecture will allow Zambia Police to have complete control of the system including how data is managed and what security measures are to be put in place.

\section{E. System Modelling}

1) Use case: The use case depicts how the users or actors interact with the system, in the proposed system there is a web and mobile application use cases. The use case for web application is shown in Fig. 7.

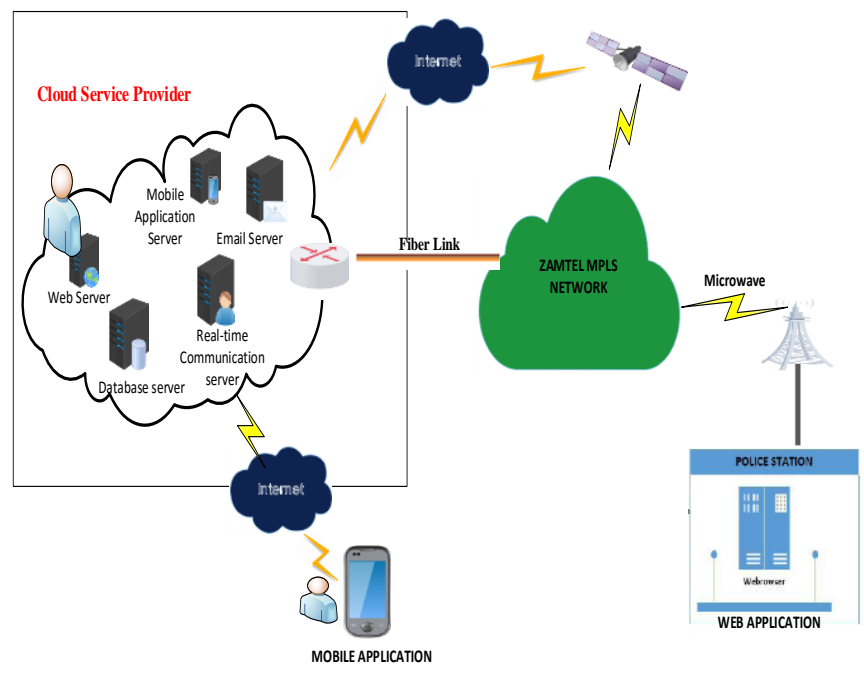

Fig. 6. Proposed System Architecture. 
As shown in Fig. 5, the main actors in the web system are; officer on duty, CIO, investigating officer \& records/statistics officer. The users at the web application first log into the system and then perform transactions like creating and updating crime cases, view reported crimes and also view generated crime maps.

The use case for mobile application is shown in Fig. 8.

As shown in Fig. 6 the main actors in the mobile app are the citizens. Users of the mobile app would be able to create an account, login, report a crime incident, add a location of crime using google map and check the status of crime case.

2) Sequence Diagram (SD): The sequence diagram depicts the flow of events in the system. Fig. 9 shows the sequence diagram (SD) for recording a case.

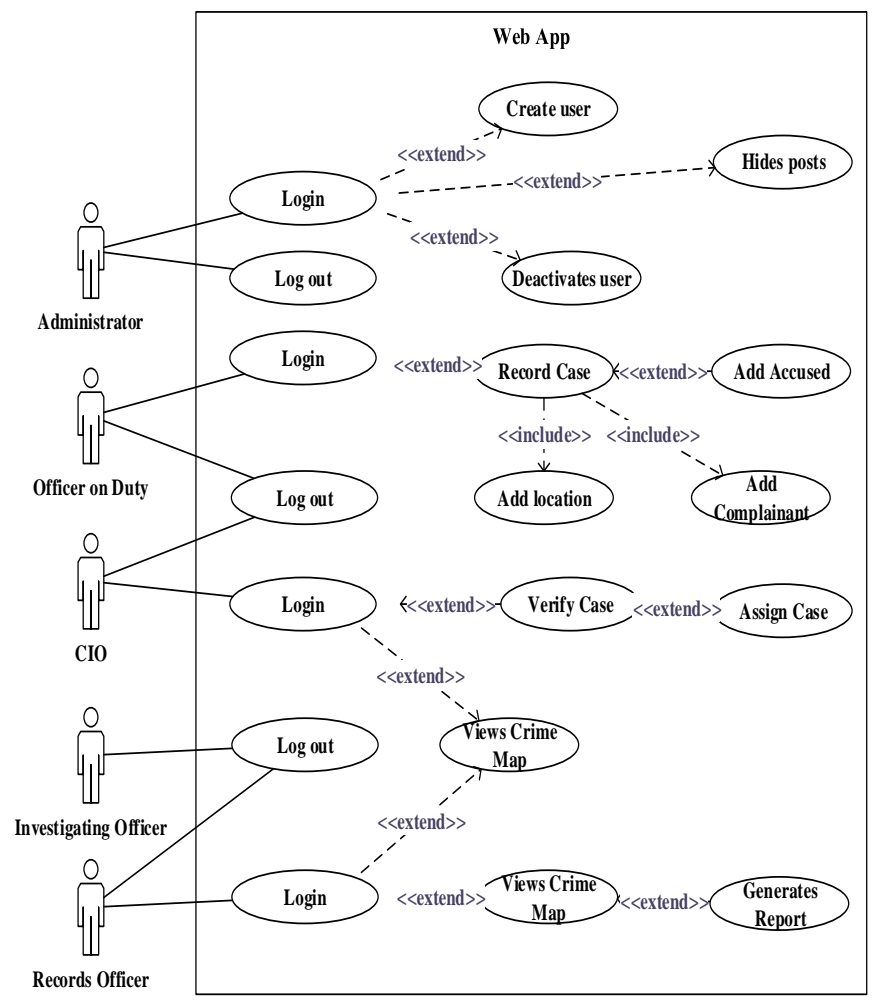

Fig. 7. Use Case - Web App.
3) Entity Relationship Diagram (ERD): The entity relationship diagram (ERD) for the proposed system is shown in Fig. 10.

The ER model diagram in Fig. 10 shows the relationships between entities and attributes in the proposed system.

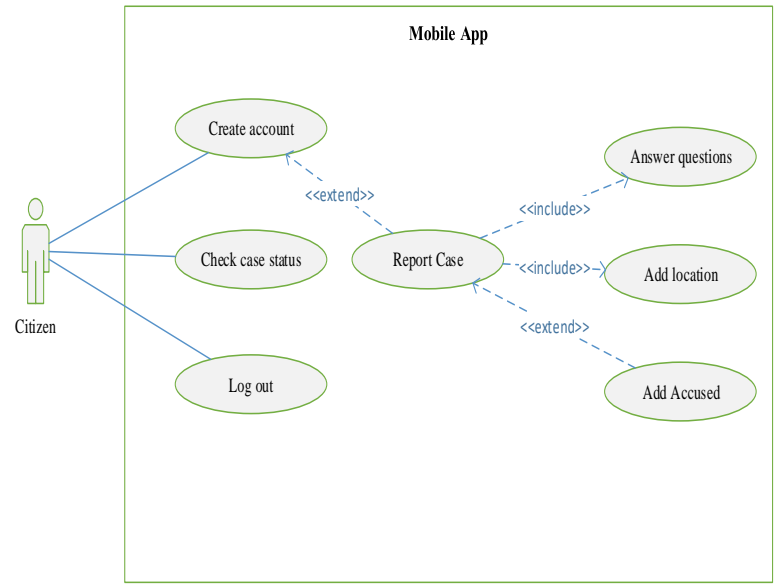

Fig. 8. Use Case-Mobile App.

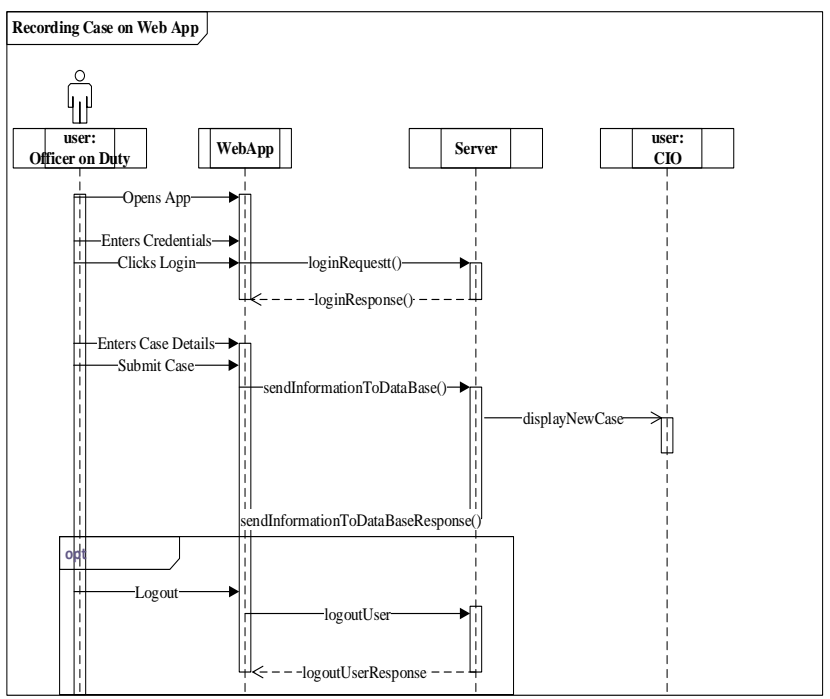

Fig. 9. Sequence Diagram -Case Recording. 


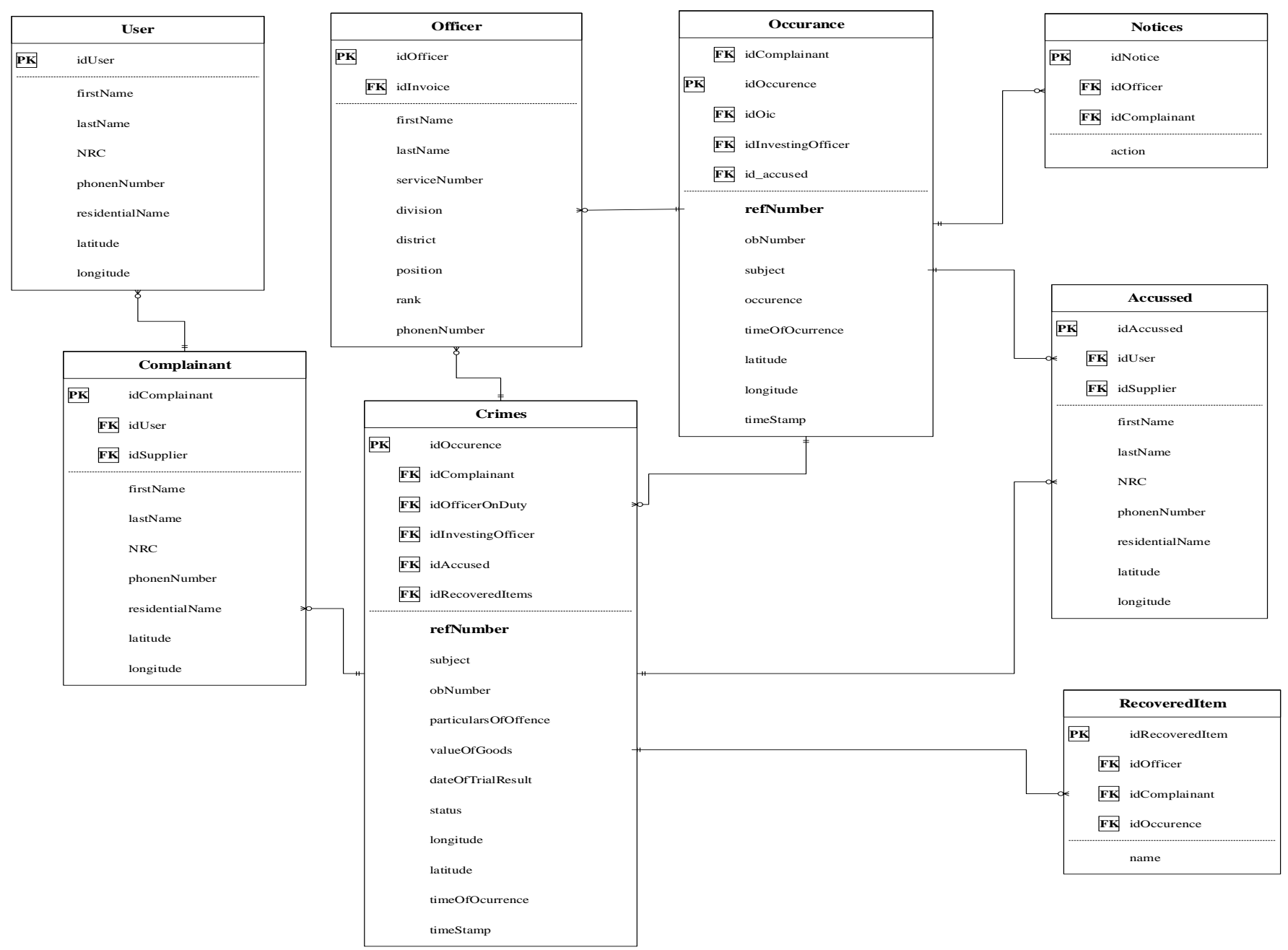

Fig. 10. Entity Relationship Diagram.

\section{RESUlTS}

The results obtained from the baseline study and system prototype development and testing are presented in this section. The main purpose of conducting the baseline study was to identify the challenges in the current crime mapping system used by the Zambia Police Service. A proposed prototype application was developed to address the challenges.

\section{A. Baseline Study}

The data collected from the baseline study was analyzed using descriptive statistics and the results were presented in different forms. A study was conducted to find out the levels of knowledge in computers among the officers in the Zambia Police, the results are shown in Fig. 11.

As shown in Fig. 11, all the officers interviewed indicated that they had at least some basic knowledge of computers, with more than $50 \%$ of the respondents indicating that their level of knowledge in computers was either good or excellent.

A study was conducted to find out on the usage of crime mapping technique in police stations, the results are shown in Fig. 12.
The results in Fig. 13 show that $85.2 \%$ of the stations conduct crime mapping using manual or physical geographical maps and pins placed on the map while $14.8 \%$ indicated that they don't use any form of crime mapping technique.

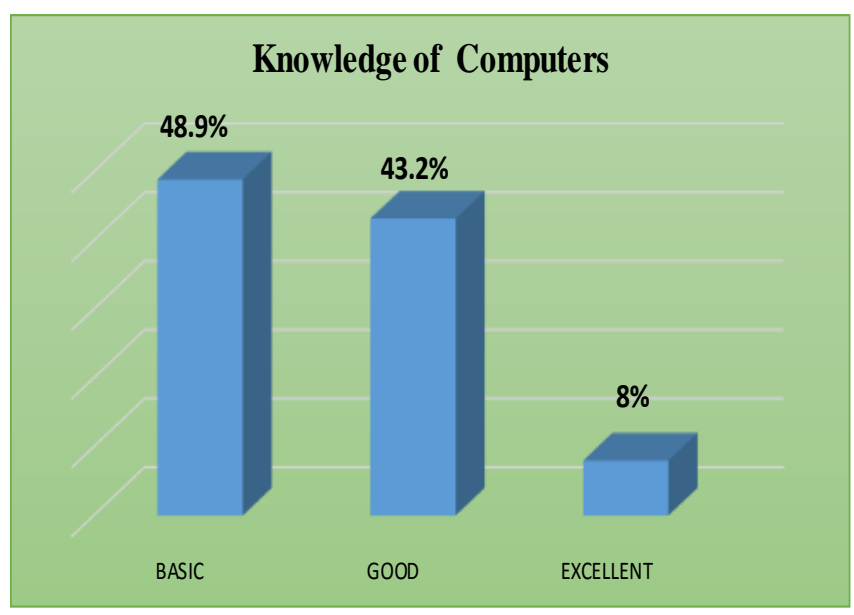

Fig. 11. Computer Knowledge. 


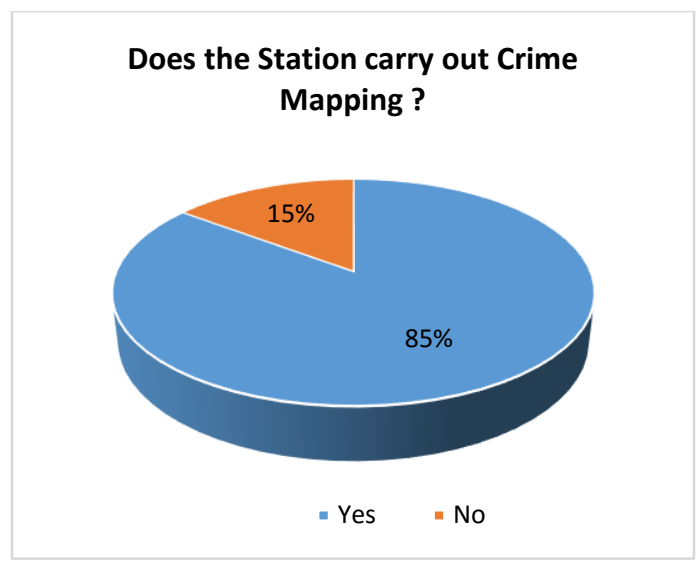

Fig. 12. Crime Mapping usage.

The study revealed that one of the challenges of the current manual system is non-instant availability of statistics or data on areas prone to crimes as indicated by $95 \%$ of respondents in Fig. 13.

As shown in Fig. 13, one of the major cause of non-instant availability of crime data is the manual storage of data that requires physical counting. The manual data does not support data querying hence data is subjected to be counted one by one to establish the desired statistics, a process which is known to be time consuming.

A total of $91 \%$ of respondents further indicated of having challenges in analyzing \& managing crime data with manual maps as shown in Fig. 14.

As shown in Fig. 14, the major weakness of physical crime map is that it does not only support querying techniques but also can only accommodate one particular crime data at time.

Further, the study looked at how crimes are reported by the general public and how the police capture and record crime data, Table I shows the crime reporting methods.

The results in Table I indicate that $75.9 \%$ of people walk to the station to report crimes. Only $24.9 \%$ make phone calls. In addition, all crime cases and statistics are manually captured, recorded, processed and stored in books \& papers. Data input is critical for the accurate of digital maps. For digital crime maps to be automated there is need to consider digitalizing the stage of reporting, capturing and recording of crime data by introducing a mobile application platform to be used by the general public to report crime case. In order to understand the type and nature of mobile devices used by the general public, questionnaires were distributed to citizens who were visiting the police stations for various reasons across Lusaka city. The results in Fig. 15 show that $86 \%$ of the general public own phones or other mobile devices that have access to internet.

The study further wished to know and uncover the type of the mobile operating systems of the mobile devices considered in the survey, the results are shown in Fig. 16.

As shown in Fig. 16, for the mobile devices that have internet access displayed in Fig. 15, 72\% of those had android operating system, $14 \%$ had Microsoft windows while only $8 \%$ have Apple and 6\% had unknown mobile operating systems.
With these results it is evident that in order for the system to be accessed by majority citizens it had to be belt on both web and android application platforms.

Is Data Instantly Available?

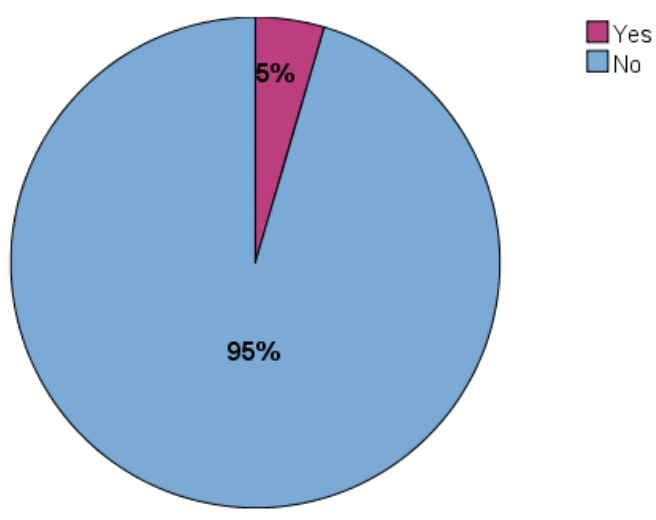

Fig. 13. Non Instant Availability of Data.

Challenges in Crime Data Management \& Visualization?

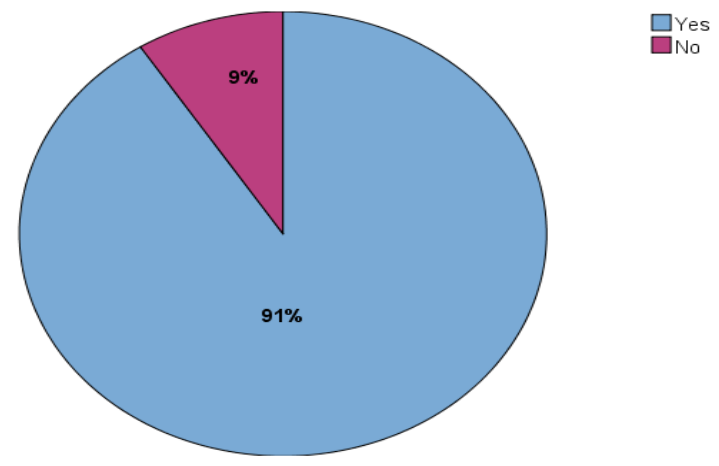

Fig. 14. Challenges in Data Management and Visualization.

TABLE. I. CRIME REPORTING METHODS

\begin{tabular}{|c|c|c|c|}
\hline \multicolumn{4}{|l|}{ How does the public report crimes? } \\
\hline & \multicolumn{2}{|c|}{ Responses } & \multirow{2}{*}{$\begin{array}{l}\text { Cumulative } \\
\text { frequency }\end{array}$} \\
\hline & Frequency & Percent & \\
\hline $\begin{array}{l}\text { Does the public walk in to the police } \\
\text { station when making crime reports? }\end{array}$ & 88 & $75.9 \%$ & $\%$ \\
\hline $\begin{array}{l}\text { Does the public make a call to the } \\
\text { police when making crime reports? }\end{array}$ & 28 & $24.1 \%$ & $31.8 \%$ \\
\hline Total & 116 & $100.0 \%$ & $\%$ \\
\hline
\end{tabular}

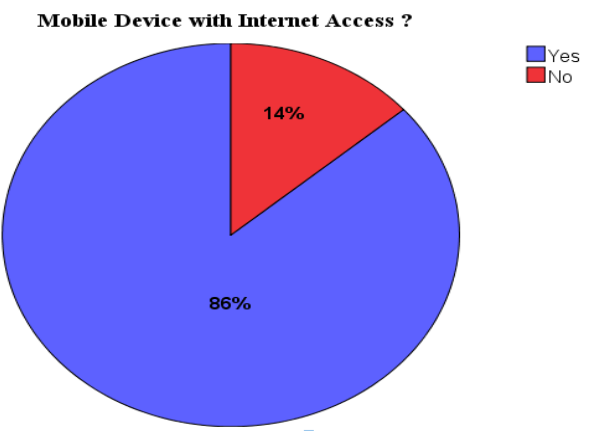

Fig. 15. Mobile Devices. 


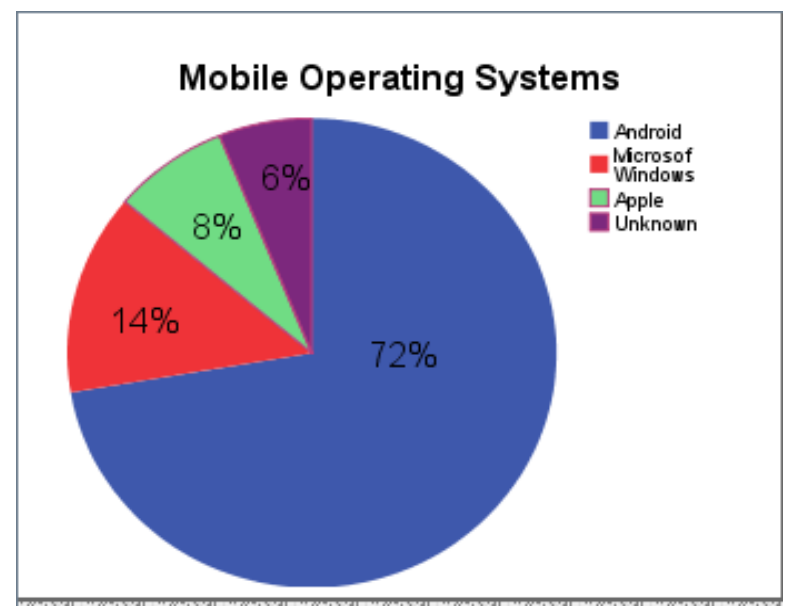

Fig. 16. Mobile Operating System.

\section{B. System Prototype Development}

As already outlined in the previous section, the prototype application named crime mapper consists of the web and android mobile platforms. The web application will strictly be used only by the police consisting of front end which is a web browser and a sever backend consisting of firebase web server and cloud firebase database for data storage. The police can use the web application to record crime incidences from the citizens who walks into the police station, generate, view and update crime maps. The android mobile application will be running on the user's mobile device which can be used to report crime incidences. Both the web application and mobile application are connected to one central database in the cloud.

1) Mobile application: The mobile application will only be used by the general public to report crime incidences, the user is required to download the application and register his or her details into the system as shown in Fig. 17.

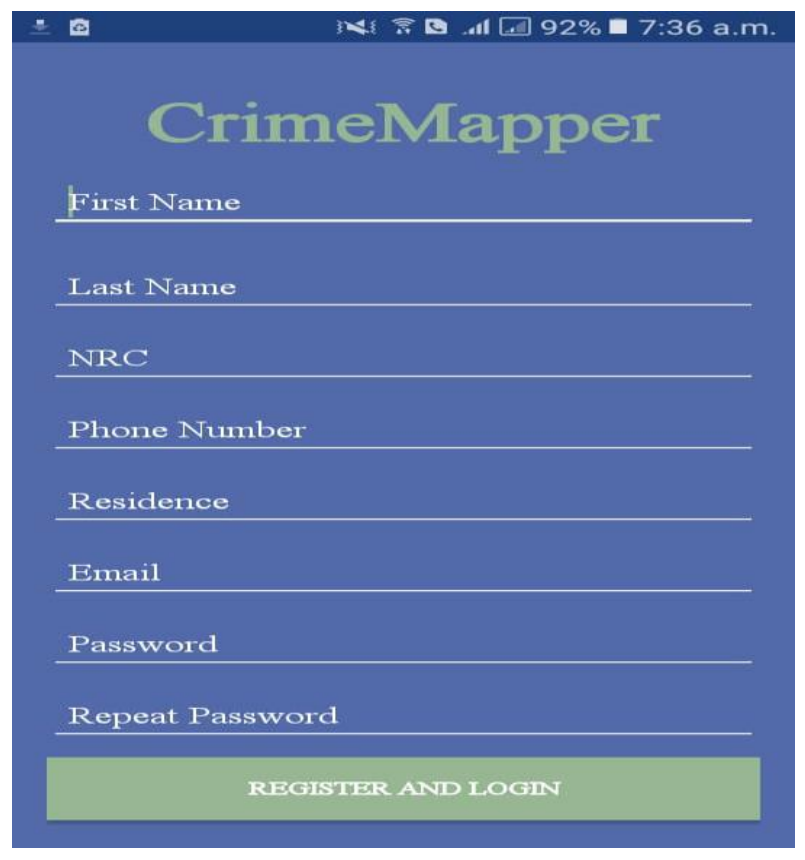

Fig. 17. User Registration - Mobile App.
As shown in Fig. 17, the registration details specified by the user will be saved into the database and displayed in the occurrence book at the police station. The next time the user wants to use the application, he or she will be prompted to sign in as shown in Fig. 18.

Once the user successfully registers or logs into the application, the system will direct the user to the crime incident reporting screen as shown in Fig. 19.

As shown in Fig. 19, the user is required to select and enter the category of crime case for example rape, murder, theft and many others. In addition, the user is required to specify the location time and location of crime incident. The location of crime is selected from the google map shown in Fig. 20.

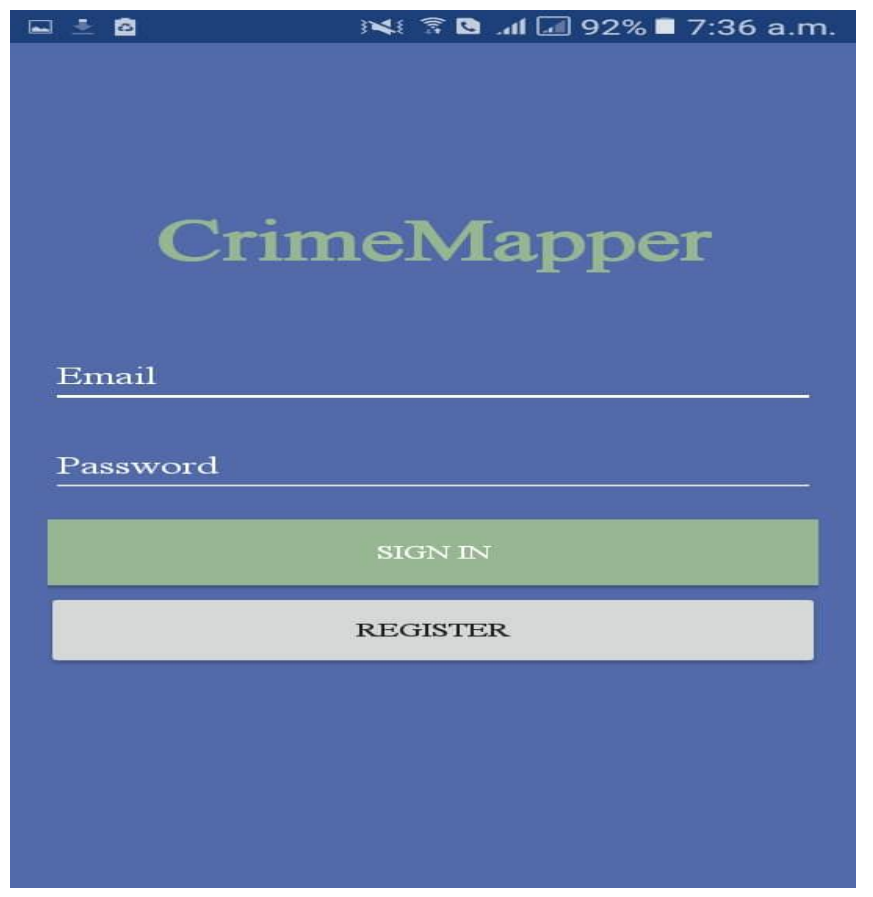

Fig. 18. Login Mobile App.

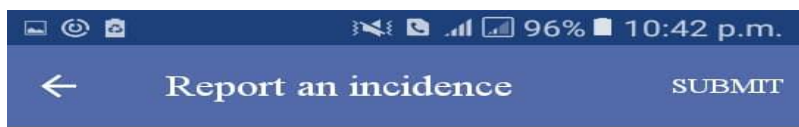

Select Category

Place of Occurence

Brief statement

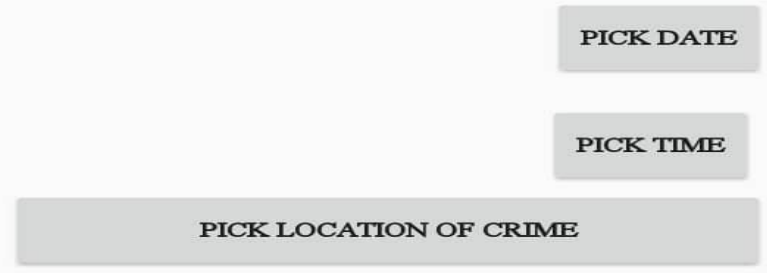

Fig. 19. Crime Reporting - Mobile App. 


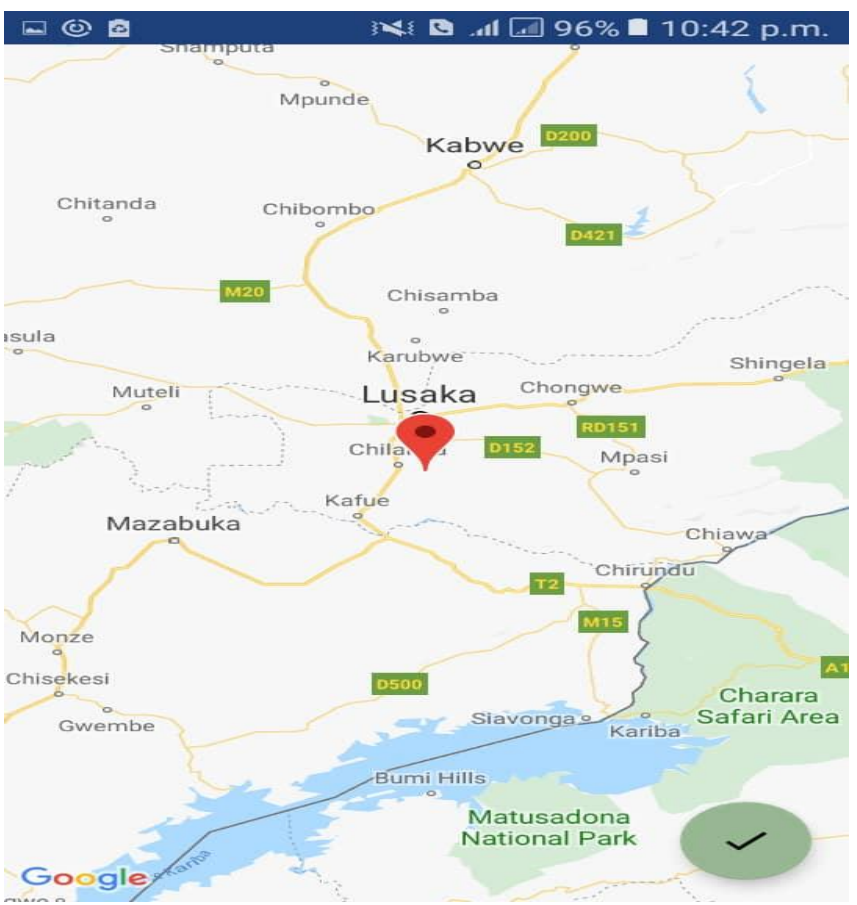

Fig. 20. Crime Location Navigator - Mobile App.

As shown in Fig. 20, the user navigates to the actual location of crime on the map, the crime location coordinated together with other crime details are saved into the occurrence book and crime register designed in the cloud database which can only be accessed by the police using the web application. Based on the crime location coordinates, the crime incident report is directed to a nearby police station. The user is able to view the status of the case they reported as shown in Fig. 21.
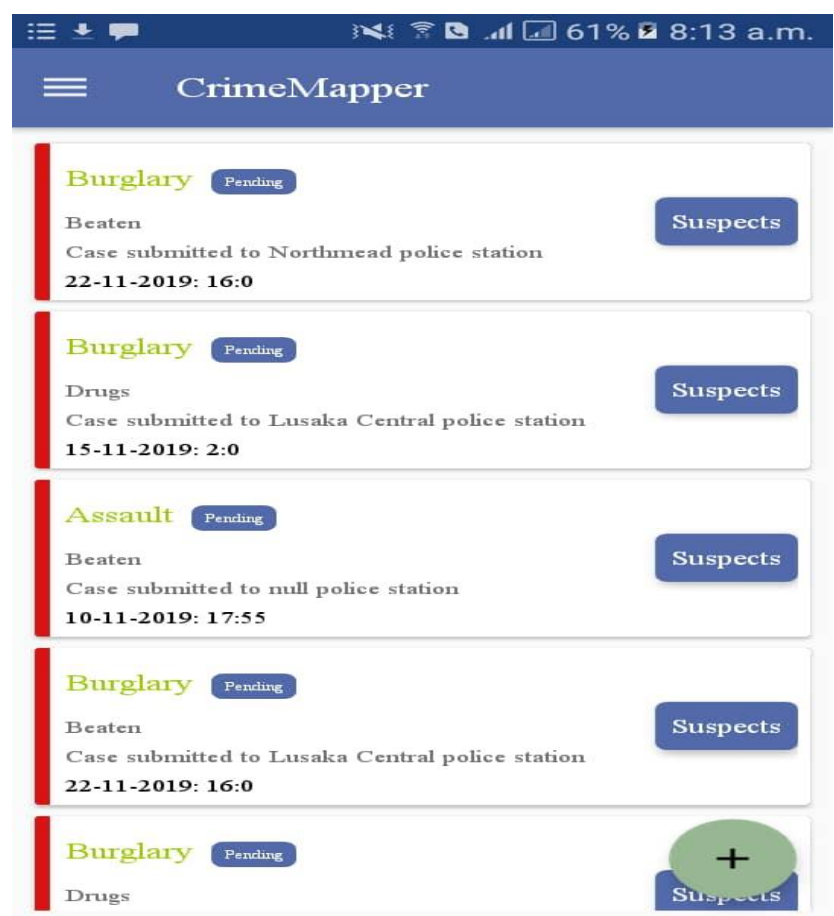

Fig. 21. Crime Status - Mobile App.
2) Web application: The web application will only be used by the police to record crime incidences from the general public that walks or physically visits the police station. The application will be used to view and generate crime maps and statistical reports. The users who are the Police Officers are required to register their details into the system as shown in Fig. 22.

If the details of the user are already captured into the application, the system prompts him or her to login as shown in Fig. 23.

When the user successfully logs into the application, the system directs to the window where crime reports are listed as shown in Fig. 24.

The user can record a new case by clicking on add new case as shown in Fig. 25.

The user can specify the location of the crime by navigating on the google map as shown in Fig. 26.

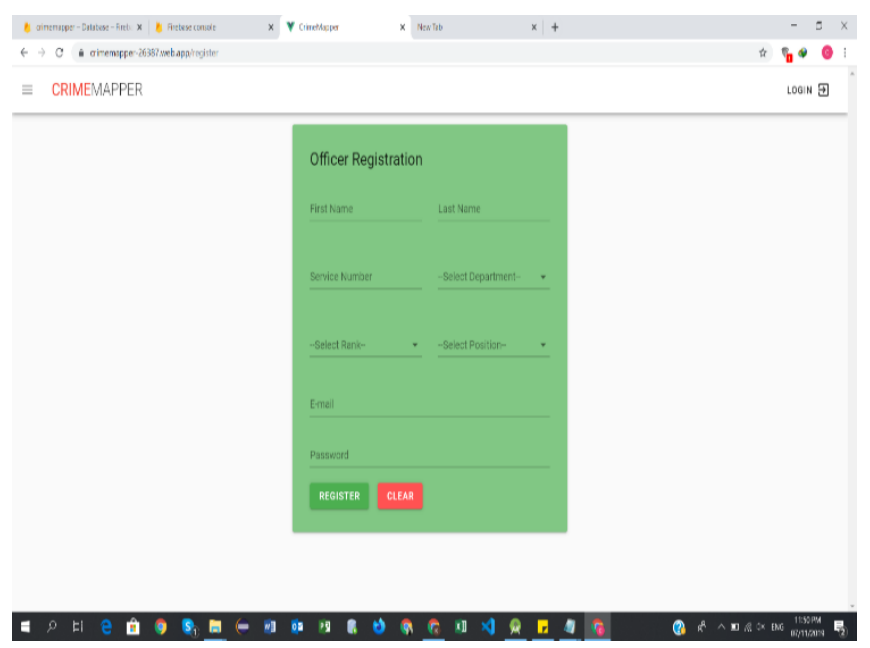

Fig. 22. User Registration - Web App.

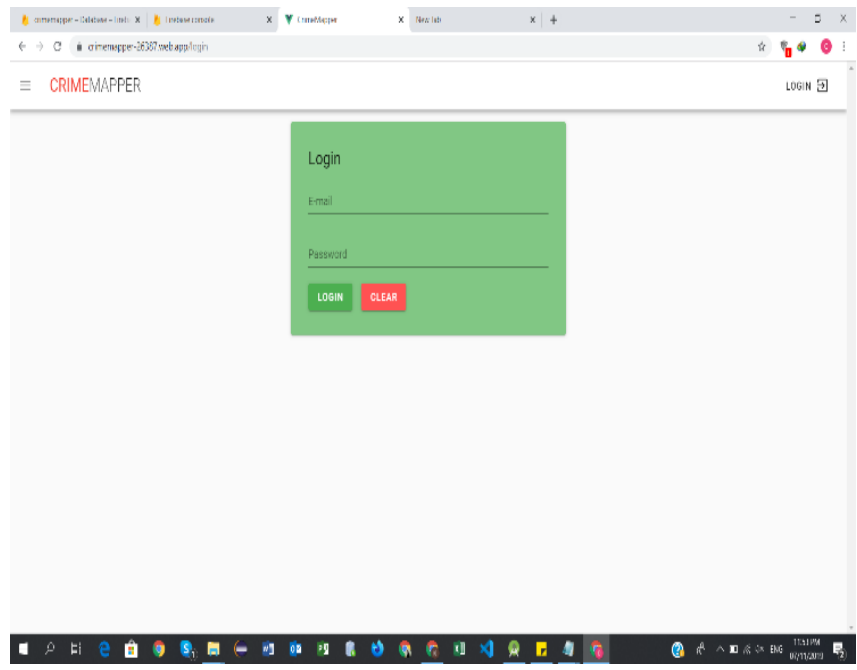

Fig. 23. Login - Web App. 


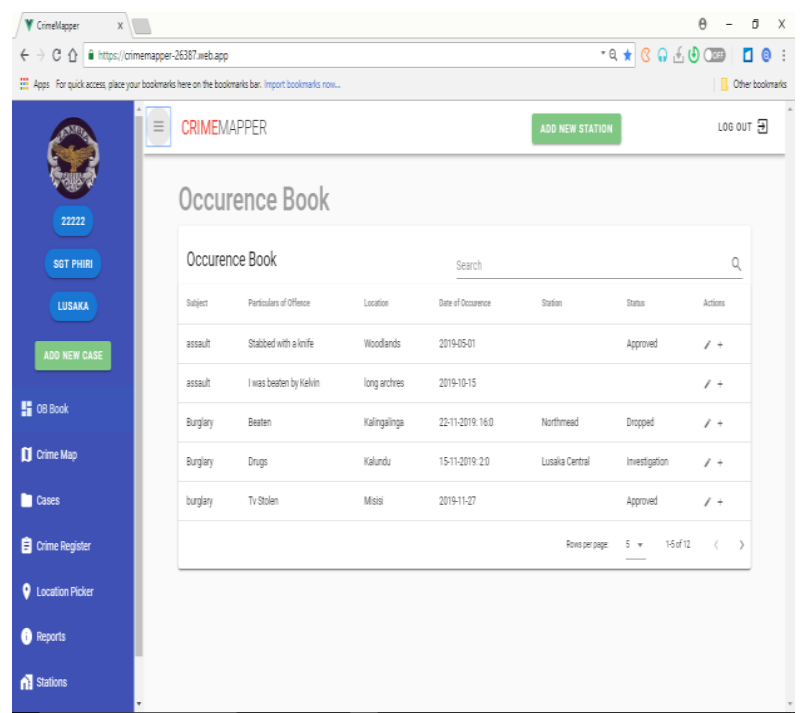

Fig. 24. Crime Reports List - Web App.

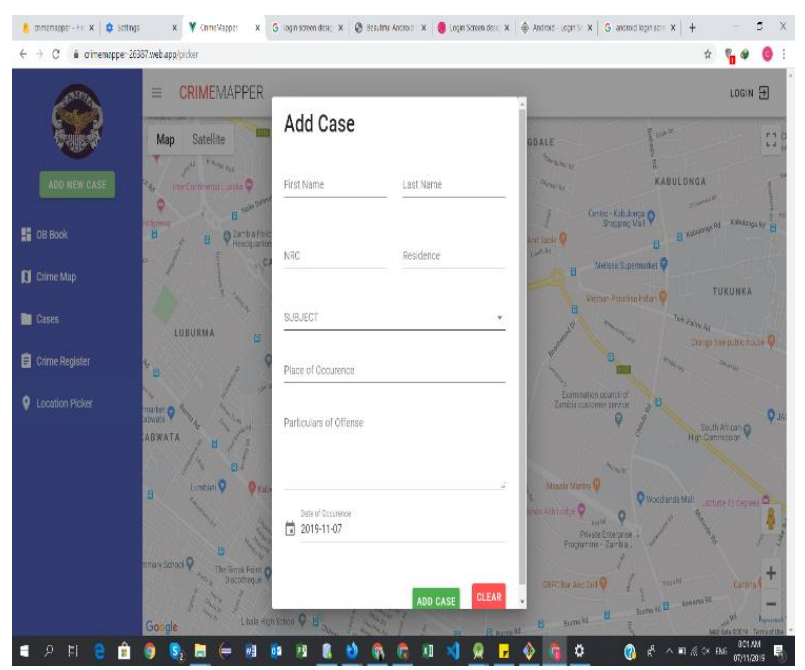

Fig. 25. Adding a Crime Report -Web App.

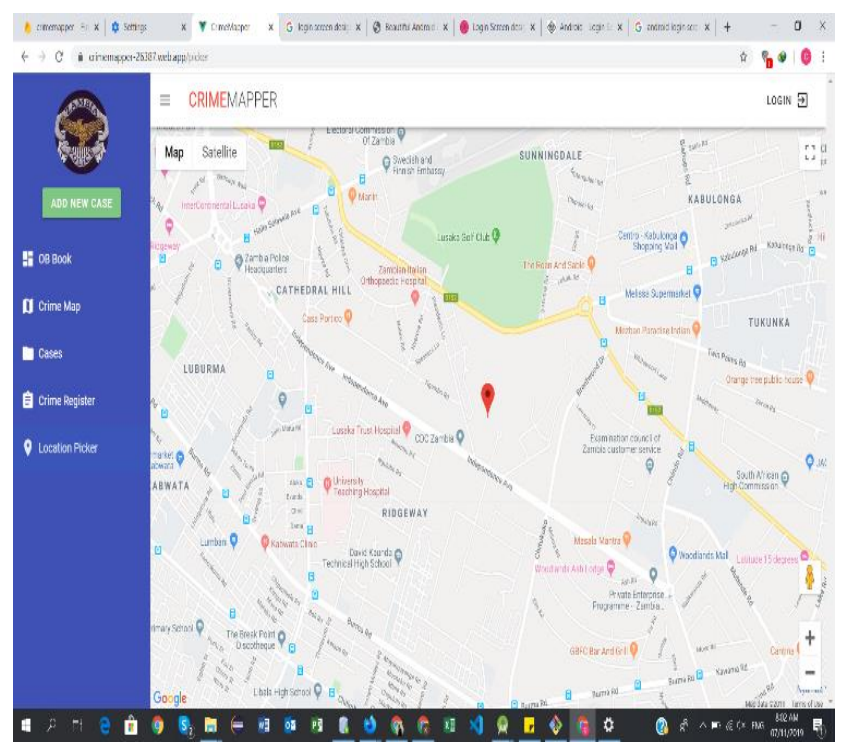

Fig. 26. Crime Location Navigator - Web App.
As shown in Fig. 26, the location navigator enables the user to select the exactly location of a crime from a Google map. The location coordinates are saved into the central database in the cloud. The screenshot window in Fig. 27 shows the filtering of the map based on the name of crime.

As shown in Fig. 27, the crime map can be filtered using the name of a crime like murder, rape, theft and others types of crime. This means a user can choose specific spatial spots to be display on the crime map.

Fig. 28 shows a screen shot window displaying sample spatial location of crime spots.

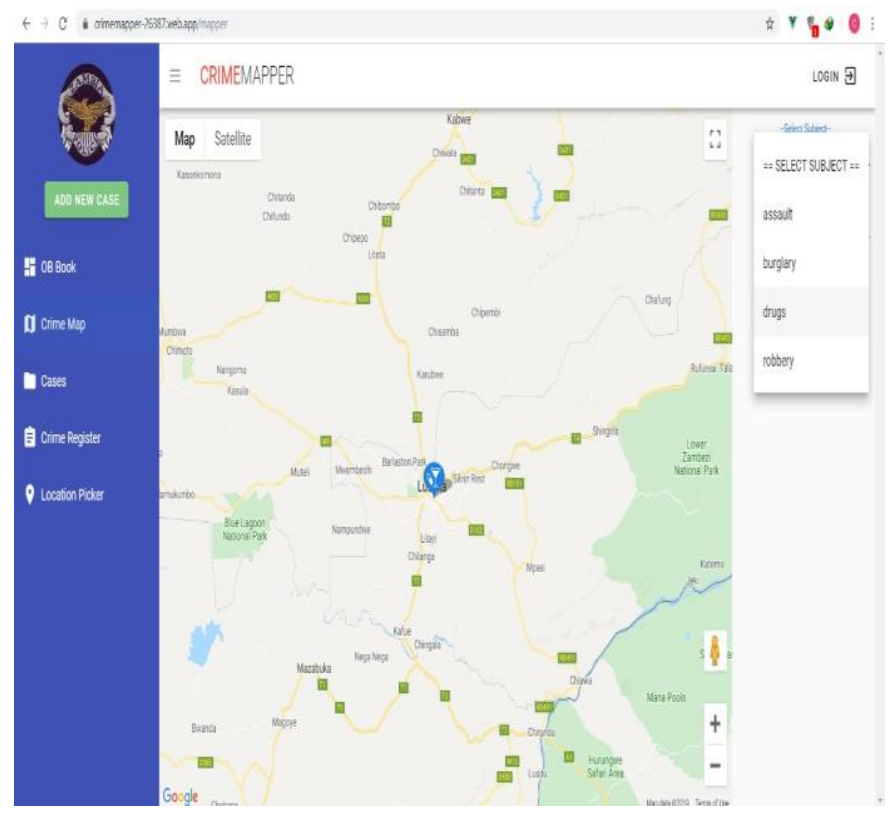

Fig. 27. Filtering Map - Web Map.

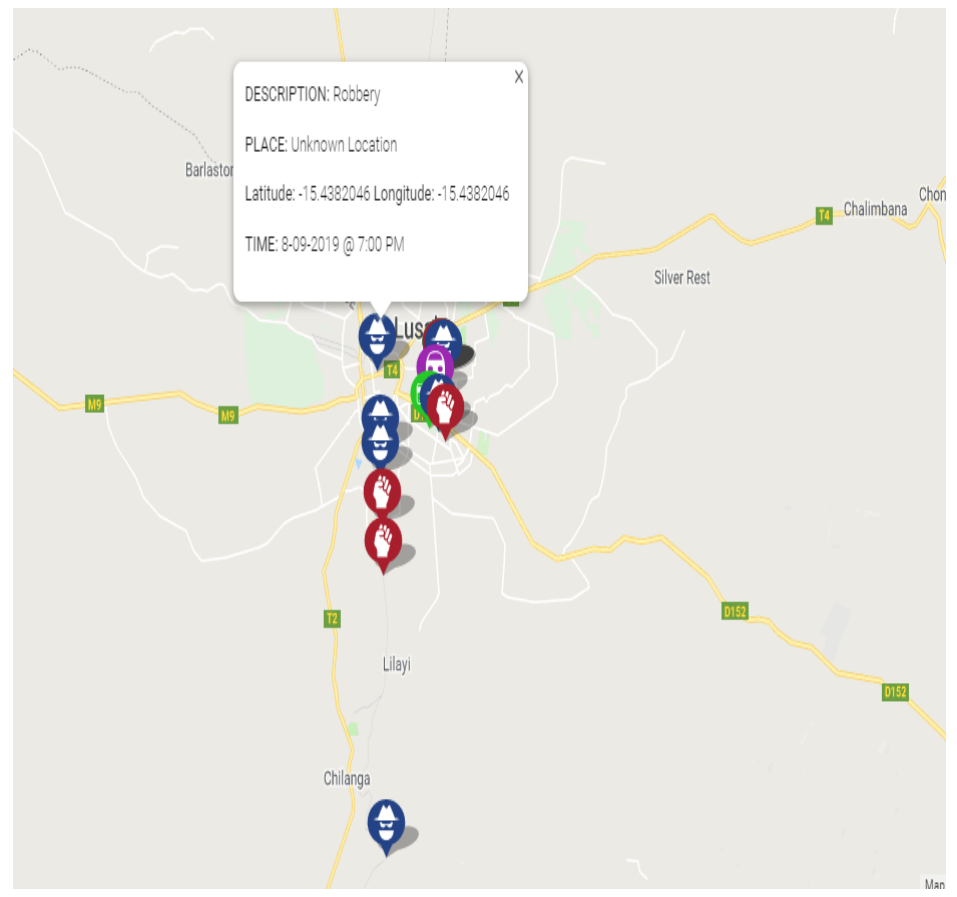

Fig. 28. Spatial Crime Spots - Web App. 
As shown in Fig. 28, the system is able to display spatial crime spots as they are being reported by the general public. Whenever a crime is reported and recorded into the system through either mobile application or web application, a pin is placed on the map representing a crime incident. Each crime sport shows name, location and its coordinates, date and time the crime was reported.

\section{DISCUSSION}

The study was aimed at identifying and establishing challenges of the current crime mapping system used by the Zambia Police service and also design a computerized crime mapping model for reporting and mapping of crimes. From the baseline study conducted, it was discovered that $85.2 \%$ of the stations considered in the study conduct crime mapping using manual or physical geographical maps and pins placed on the map while $14.8 \%$ indicated that they don't use any form of crime mapping technique. The study revealed that one of the challenges of the current manual system is non-instant availability of statistics or data on areas prone to crimes as indicated by $95 \%$ of respondents, the major attribute to this challenge is the manual storage of data that requires physical counting. The manual data does not support data querying hence data is subjected to be counted one by one to establish the desired statistics, a process which is known to be time consuming. The study further showed that total of $91 \%$ of respondents further indicated of having challenges in analyzing \& managing crime data with manual maps, some of the weakness of physical crime map include not support querying techniques and also can only accommodate one particular crime data at time. The study also looked at how crimes are reported by the general public and how the police capture and record crime data, results indicated that $75.9 \%$ of people walk to the station to report crimes. Only $24.9 \%$ make phone calls. In addition, all crime cases and statistics are manually captured, recorded, processed and stored in books \& papers. For digital crime maps to be automated and implemented there is need to consider digitalizing the stage of reporting, capturing and recording of crime data. The study introduced mobile and web application platforms to be used to capture crime reports. The crime data captured from both the web application and Mobile application should be stored in one central cloud database.

In order to understand the type and nature of mobile devices used by the general public, questionnaires were distributed to citizens who were visiting the police stations for various reasons across Lusaka city. The results show that $86 \%$ of the general public own phones or other mobile devices that have access to internet. The study further wished to know and uncover the type of the mobile operating systems of the mobile devices considered in the survey, the results indicated that $72 \%$ of those had android operating system,14\% had Microsoft windows while only $8 \%$ have Apple and 6\% had unknown mobile operating systems. With these results it is evident that in order for the system to be accessed by majority citizens it had to be belt on both web and android application platforms.

The current business processes were mapped as indicated in Fig. 3 and a model based on cloud architecture and spatial data was developed as indicated in Fig. 4 and Fig. 5. In order to mitigate the challenges faced by Zambia Police in crime mapping and crime data management, a computerized crime mapping model based on cloud and spatial data was developed, comprising of web application and android mobile application platforms respectively all connected to a central firebase cloud database. The web application will only be used by the Police to not only generate and view crime maps but also capture and record crime reports from the general public. The mobile application will only be used by the general Public to report crime cases to the police. Spatial crime spots are added to the map in real time as crime cases are reported. The test results of the prototype show improved data capture of crime cases and also improved crime data visualization through generated crime maps. Crime maps can be filtered based on the name of crime like murder, theft, rape and other type of crimes. The developed prototype test results also proved that it is more efficient and effective than the current system. For an institution like Zambia Police that is still depending on papers and books for its daily operations, implementing the automated crime mapping system would be a good starting point towards utilization and usage of ICT in Zambia Police Service.

\section{CONCLUSION}

The baseline study was conducted and a number of challenges were identified in the current manual system such as manual capturing and recording of crime reports, non-instant availability of crime data of areas with high crimes, poor crime data management, poor data visualization and many others. The study proposed a computerized crime mapping model based on cloud and spatial data to address the challenges in the current system used by the Zambia Police. The current business processes were mapped and a crime mapping model was designed and developed in order to address the challenges that were discovered in the baseline study. The model is based on the Cloud Architecture, Android Mobile Application, Web Application, Google Map API and Java programming language. Test results of the developed prototype system shows improved spatial crime data visualization and reporting of crime data with reduced dependency on manual transactions, it also proved to be more effective than the current system.

\section{RECOMMENDATION AND FUTURE WORKS}

\section{A. Recommendations}

The study has revealed that the automated crime mapping system is desirable. With the police personnel that exhibited high levels of knowledge in computers including a general population that is drifting towards the use of ICT, we recommend the adoption of the proposed model as it will improve the work efficiency within the Police Service.

\section{B. Future Works}

Some future works that can be done on this system include;

1) The crime dataset generated through crime reporting platforms in this system can be integrated with machine and deep learning techniques to predict future crime occurrences crime hotspot areas.

2) Introducing case docket management would add value to the system. A case docket contains information like address and date of crime, statements, reports from experts, witnesses, 
details of complainants and suspects. The public prosecutor makes use all the information in the case docket to present a case in the court of law.

\section{ACKNOWLEDGMENT}

We would like to thank the Zambia Police Service for the support and also for providing us with all relevant information towards this project. Special thanks goes to UNZA Department of Computer Science and Department of Electrical and Electronic Engineering for the advice and expertise rendered to this project.

\section{REFERENCES}

[1] S. Anurag and S. Baghel, "A Predictive Model for Mapping Crime using Big Data Analytics," International Journal of Research in Engineering and Technology, vol. 4, no. 4, pp. 343-348, 2015.

[2] H. Kumar, B. Sainia, and G. Mahajana, "Crime Prediction \& Monitoring Framework Based on Spatial Analysis," in International Conference on Computational Intelligence and Data Science, Jaipur, 2018.

[3] V. Kappeler, "What is the Place of Police within the Criminal Justice System?" Eastern Kentucky University, October 2012. [Online]. Available: http://plsonline.eku.edu/insidelook/what-place-police-withincriminal-justice-system. [Accessed 5 Novermber 2016].

[4] Correctionalofficer.org, " $\quad$ U.S Criminal Justice System," correctionalofficer.org, [Online]. Available: http://www.correctional officer.org/us-criminal-justice-system. [Accessed 13 November 2016].

[5] Department of Justice and Equality, "White paper on crime-The Community and the Criminal Justice System," Department of Justice and Equality, Dublin, 2011.

[6] Zambia Police, "Zambia Police History," Zambia Police,2008.[Online]. Available: https://www.google.co.zm/?gws_rd=cr\&ei=Pb0aWL3JJciUsg G3ka34Ag\#q=history+of+zambia+police+service. [Accessed 29 October 2016].

[7] C.Chandrasekar and M.Kuma, "GIS Technologies in Crime Analysis and Crime mapping," International Journal of Soft Computing and Engineering (IJSCE), vol. I, no. 5, pp. 115-122, 2011.

[8] D. Wang and D. Wei, "Crime hotspot mapping using the crime related factors - a spatial data mining approach," Springer Science+Business Media, New York , 2012.

[9] P. Kedia, "Crime Mapping and Analysis using GIS," International Institute of Information Technology, vol. 1, no. 1, pp. 1-15, 2016.

[10] G. Breetzke, "Geographical Information System (GIS) And Policing In South Africa- A Reveiw," Policing: An International Journal of Policing Strategies and Management, vol. 29, no. 4, pp. 723-740, 2007.

[11] G. Lamond, "What is a Crime?, “ Oxford Journal of Legal Studies, vol. 27, no. 4, pp. 609-632, 2007.

[12] K. Harries, Mapping Crime:Principle and Practice, Washington: National Institute of Justice, 1999.

[13] M. Gluck and L. Yu, "Geographic Information Systems," Advances in Librarianship, vol. 1, no. 1, pp. 1-38, 2015.

[14] K. Hansgen, "Crime Mapping In Law Enforcement: Identifying Analytical Tools, Methods, And Outputs," CULMINATING PROJECTS IN CRIMINAL JUSTICE, vol. 1, no. 1, pp. 1-248, 20 October 2016.

[15] C. W. Bruce, "Library-CrimeAnalysis," 3 August 2013. [Online]. Available: http://www.justiceacademy.org/iShare/Library-CrimeAnalysis /CrimeMapping\&Analysis.pdf. [Accessed 28 October 2019].

[16] U. Argun and M. Dağlar, "Crime Mapping and Geographical Information Systems in Crime Analysis," International Journal of Human Sciences, vol. 13, no. 1, pp. 1-14, 2016.
[17] A. Murray and J. Western, "Exploratory Spatial Data Analysis Technologies For Examining Urban Crime.," Center for Crime and Justice Studies, vol. 1, no. 1, pp. 1-21, 2001.

[18] S. Chun, V.Avinash and S. Yuan, "Crime Prediction Model using Deep Neural Networks," in Annual International Conference on Digital Government Research, Dubai, 2019.

[19] N. Waduge, "Machgine Learning Approaches for Detecting Crimes," Researchgate, vol. 1, no. 1, pp. 1-7, 2017.

[20] K. Das, R. Behera, "A Survey on Machine Learning: Concept Algorithms and Applications," International Journal of Innovative Research in Computer and Communication Engineering, vol. 5, no. 2, pp. 1301-1309, 2017.

[21] A.Simon, M.Singh ,S. Venkatesan and R. Babu, "An Overview of Machine Learning and its Applications," International Journal of Electrical Sciences \& Engineering, vol. 1, no. 1, pp. 22-24, 2015.

[22] A. Dey, "Machine Learning Algorithms: A Review," International Journal of Computer Science and Information Technologies, vol. 7, no. 3, pp. 1174-1179, 2016.

[23] S. Das,A.Dey,A.Pal and N. Roy " Applications of Artificial Intelligence in Machine Learning: Review and Prospect," International Journal of Computer Applications, vol. 115, no. 9, pp. 975-987, 2015.

[24] H.Woo and H.Kang, "Prediction of crime occurrence from multi-modal data using deep learning," 24 April 2017. [Online]. Available: https://journals.plos.org/plosone/article?id=10.1371/journal.pone.017624 4. [Accessed 10 November 2019].

[25] A.Simon, M. Singh ,S. Venkatesan and R. Babu, "An Overview of Machine Learning and its Applications," International Journal of Electrical Sciences \& Engineering, vol. 1, no. 1, pp. 22-24, 2015.

[26] Ben. Benuwa, Y. Zhan, B.Ghansah,D. Keddy and F. Kataka, "A Review of Deep Machine Learning," International Journal of Engineering Research in Africa, vol. 24, no. 1, pp. 124-136, 2016.

[27] I. Namatēvs, "Deep Convolutional Neural Networks: Structure Feature Extraction and Training," Information Technology and Management Science, vol. 20, no. 1, p. 40-47, 2017.

[28] X. Li and Z. Liu, "A Spatial Data Security Model Under the Cloud Environment," Proceedings of the 2nd International Conference On Systems Engineering and Modeling, vol. 1, no. 1, pp. 1-4, 2013.

[29] K. Kavitha, "Study on Cloud Computing Model and its Benefits, Challenges," International Journal of Innovative Research in Computer and Communication Engineering, vol. 2, no. 1, pp. 1-9, 2014.

[30] M. Ahmad and R. Khan, "The Cloud Computing: A Systematic Review," International Journal of Innovative Research in Computer and Communication Engineering, vol. 5, no. 3, pp. 66-75, 2015.

[31] TutorialsPoint, "Cloud Computing Architecture," tutorialspoint.com, 2006. [Online]. Available: https://www.tutorialspoint.com/cloud computing/cloud_computing_architecture.htm. [Accessed 20 November 2019].

[32] S. Q. Yang, "Move into the Cloud, shall we?" Library Hi Tech News, vol. 26, no. 1, pp. 4-7, 2012.

[33] R. M. Willet, "Cloud computing assurance - A review of literature guidance," Information and Computer Security, vol. 26, no. 1, pp. 2-33, 2017.

[34] A.Shashikumar and M. Chandrashekhar , "Cloud Computing Services and Deployment Models," International Journal for Research in Applied Science \& Engineering Technology (IJRASET), vol. 5, no. 6, pp. 1083$1088,2017$.

[35] C. Rao and R. Kumar, "Cloud Computing Services And Deployment Models," International Journal Of Engineering And Computer Science, vol. 2, no. 12, pp. 3389-3392, 2013. 
[36] T. Diaby and B. Rad, "Cloud Computing: A review of the Concepts and Deployment Models," Information Technology and Computer Science, vol. 6, no. 1, pp. 50-58, 2017.

[37] G. Huilian and X. Wang, "Cloud-based Service for Big Spatial Data Technology in Emergence Management," Henan Polytechnic University, jiaozuo, 2001.

[38] N. Mwansa and J. Phiri, "Real-Time Data Capture Model for Accelerated Payment of Small-Scale Farmers," American Journal of Engineering and Applied Sciences, vol. 11, no. 3, pp. 1164-1177, 2018.

[39] C. Mamalian \& N.LaVigne, "The Use of Computerized Crime Mapping by Law Enforcement: Survey Results," USA National Institute of Justice, Washington, 1999.

[40] P. Chamikara \& J. Gunathilake, "Intelligent Crime Mapping System," University of Peradeniya, KAndy, 2012.

[41] G. D. Breetzke, "Geographical Information Systems (GIS) and Policing in South Africa- A Review," An International Journal of Policing Strategies and, vol. I, no. 3, pp. 1-82, 2007.
[42] H. Tong, "A Crowdsourcing Based Crime Mapping System," Waseda University, Tokyo, 2014.

[43] H. Singh, R. Kumar, A. Singh, P.K. Litoria, "Cloud GIS for Crime Mapping," International Journal of Research in Computer Science, vol. 2, no. 3, pp. 57-60, 2012.

[44] D. Summerton, D. Mazeika, "The impact of geocoding method on the positional accuracy of residential burglaries reported to police," Policing: An International Journal of Police Strategies \& Management, vol. 40, no. 2, pp. 2-15, 2017.

[45] O.Hutt, K. Bowers, S.Johnson and T. Davies, "Data and evidence challenges facing place-based policing," Policing: An International Journal of Police Strategies \& Management, vol. 41, no. 3, pp. 339-351, 2018.

[46] M. Mwiya, J. Phiri and G. Lyoko, "Public Crime Reporting and Monitoring System Model Using GSM and GIS Technologies: A Case of Zambia Police Service," International Journal of Computer Science and Mobile Computing, vol. 4, no. 11, pp. 207-226, 2015. 